\title{
Power System and Energy Storage Models for Laser Integration on Naval Platforms
}

\author{
A.L. Gattozzi, J.D. Herbst, R.E. Hebner \\ Center for Electromechanics, University of Texas \\ Austin, Texas \\ a.gattozzi@cem.utexas.edu
}

\author{
J.A. Blau, K.R. Cohn, W.B. Colson, J.E. Sylvester, M.A. \\ Woehrman \\ Physics Department, Naval Postgraduate School \\ Monterey, California
}

\begin{abstract}
High power solid state laser systems are being developed for advanced weapons and sensors for a variety of Department of Defense applications including naval surface combatants. The transient power and cooling requirements of these emerging technologies present significant challenges to the electric power distribution and thermal management systems, particularly for applications requiring back fit of the new systems onto existing platforms with limited electric power generation and cooling capacities.
\end{abstract}

The University of Texas Center for Electromechanics (UT-CEM) and the Naval Postgraduate School (NPS) have collaborated in the development of simulation models of ship power systems to evaluate and help guide the integration of pulsed laser loads onto existing ship platforms. Key to the success of these efforts is the definition of a suitable energy storage system to handle the effect of the transient load.

This paper reports on the progress of detailed MatLab/Simulink models of a destroyer class ship service electric power distribution system that have been developed to evaluate the performance of battery, flywheel, and capacitor energy storage in support of laser weapons. The models allow the user to develop comparative studies of the three energy storage systems in regard to several relevant metrics that can be used for their discrimination. Examples of some of these results based on the simulations are given.

Keywords-Laser, Laser Integration, Energy Storage, Naval Power Systems

\section{INTRODUCTION}

The Directed Energy Group at the Naval Postgraduate School (NPS) and the University of Texas Center for Electromechanics (UT-CEM) are collaborating to develop simulation models of electrical power systems on specified naval platforms. These new models include modules for solid state laser (SSL) weapon systems at several output levels along with modules for various energy storage technologies. The new models leverage past experience of NPS and UT-CEM in jointly developing power system models of electric ships with laser weapons over the course of a collaborative effort over the last ten years [1-5].

These new technologies, with their still relatively low efficiencies and transient power requirements, present significant challenges to the electric power distribution and thermal management systems of a ship. This is particularly true for applications requiring retrofitting these new systems onto existing naval platforms with limited excess electric power generation and cooling system capacities. However, ship designers may find it difficult to justify the installation of enough power capacity and thermal management systems even on new ships in order to handle all expected loads, particularly since some of the largest loads may be used only sporadically. Therefore, the use of suitable energy storage systems in support of these large but intermittent loads seems quite likely: these "energy magazines" would provide the necessary power when needed by the loads, and then be recharged during downtime. Regarding operational specifications, the energy magazine should allow for a sustained engagement against multiple targets probably lasting several minutes. Ideally, it would charge up as fast as it discharges, allowing for indefinite use as long as there is ship's fuel to expend.

Three types of energy storage methods have been investigated in the course of this research program: batteries (both lead-acid and lithium- ion), flywheels, and capacitors. Three different laser power levels likely to be employed within the next decade have also been considered: $30 \mathrm{~kW}, 60 \mathrm{~kW}$, and $125 \mathrm{~kW}$ optical power output. All possible combinations of storage technology and laser power have been explored in the course of this cooperative program and, to date, this cooperation between NPS and UTCEM has resulted in two Masters Theses awarded at NPS to Navy officers using the simulation models developed in the course of this effort [6][7].

It was assumed that the laser weapon would be installed as a back-fit into the existing platform of a destroyer class ship. Therefore, a detailed model was developed for the electrical system of a destroyer class ship: the model was constructed so as to duplicate the actual distribution of electrical equipment into electrical "zones": thus, the user of the model can quickly orient himself thanks to this one-to-one mapping between model and electrical schematics (Figure 1).

This work was sponsored in part by the Office of Naval Research. 


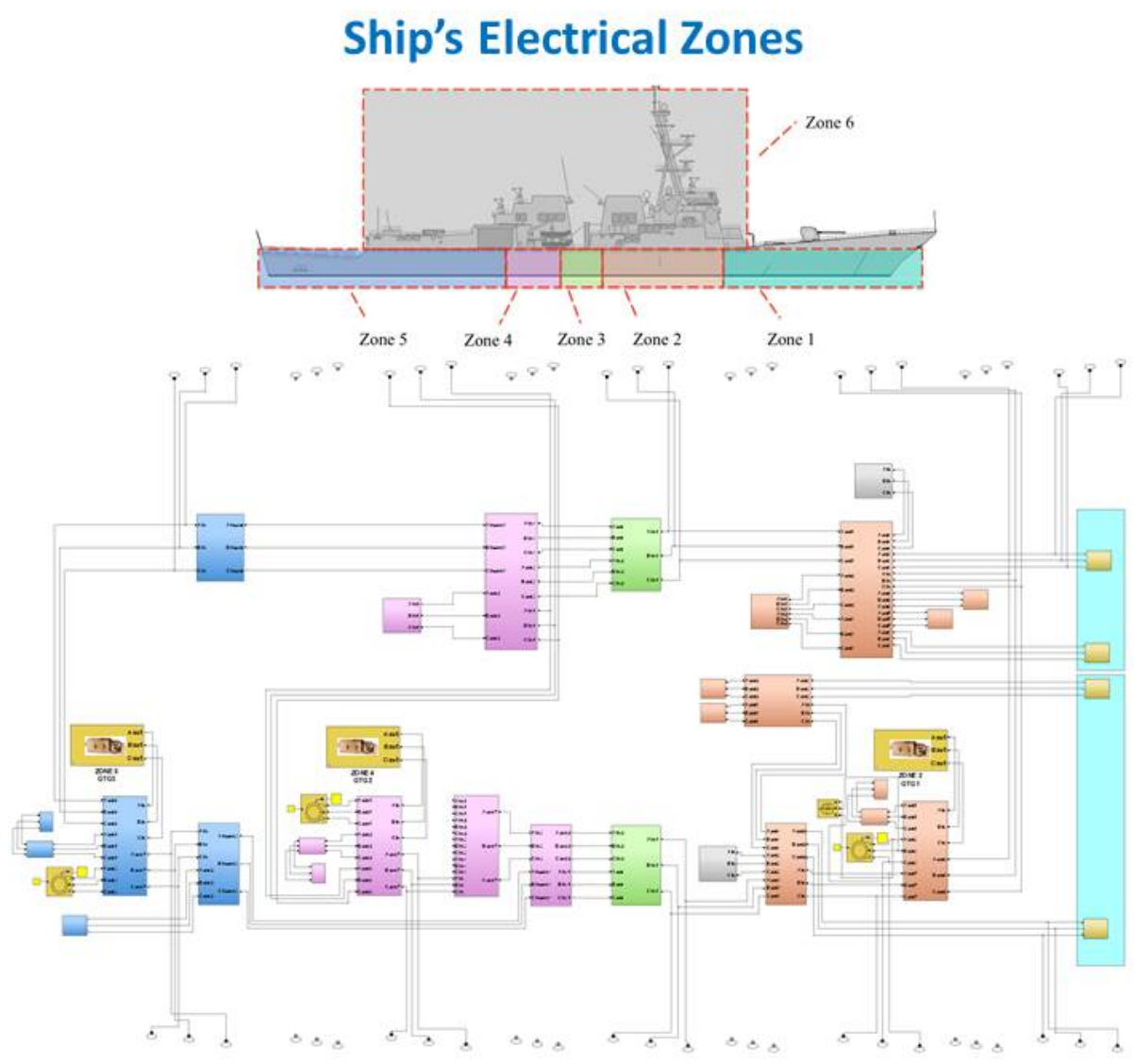

Figure 1: Ship's model internal structure showing the one-to-one mapping to the ship's electrical zones.

For ease of use of the model, power from both the port and starboard ac busses was made available at regular intervals along the ship so that external equipment could be connected without having to change the basic electrical architecture of the ship. These power taps are evident also in Figure 1. The same ship model was used for all combinations of load and energy storage studied.

\section{MODELS AND SIMULATION RESULTS}

\section{A. Lead-Acid Batteries}

Figure 2 shows the macroscopic diagram of the model of a destroyer class ship retrofitted with a SSL and supported by a lead-acid battery energy storage system. The lead-acid battery model is based on the Genesis XE70 battery by Enersys. It was assumed that the laser load would be powered by both port and starboard power busses for security. An automatic bus transfer (ABT) controller was used to insure that power to the laser was always available from one of the two busses. The incoming 450 Vac power is then transformed up in voltage and rectified resulting in a 1,000 Vdc bus available for charging the battery when the laser is not powered. A battery management system (BMS) interfaces the battery energy storage to the ship power system on one side and to the laser load on the other. The laser is fired only under battery power and during that time the battery is disconnected from the ship power. When the laser is not fired, the battery is disconnected from the laser and reconnected to the ship power from which it is then recharged. 


\section{Destroyer with Laser Load and Battery Storage}

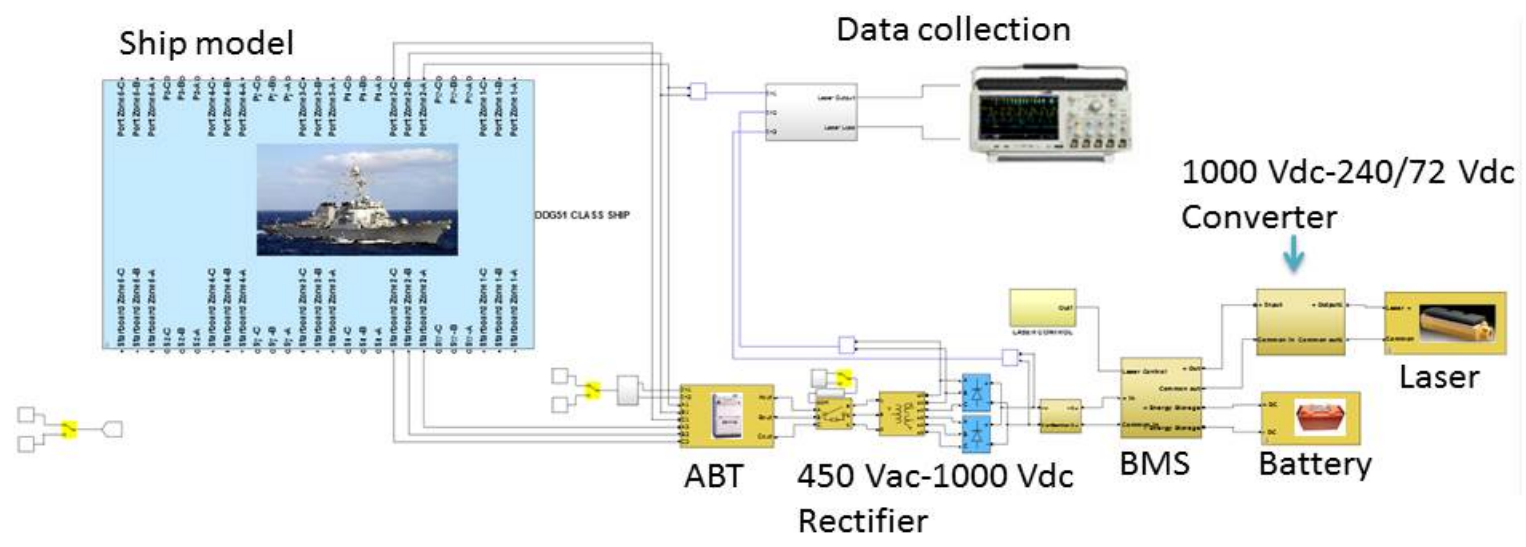

Figure 2: Diagram of destroyer class ship with SSL and battery energy storage $(\mathrm{ABT}=$ automatic bus transfer, BMS $=$ battery management system).

It is clear that in this mode of operation the critical parameters are the laser power rating, the laser duty cycle, the size of the battery energy storage, the battery charge-discharge characteristics, and the length of the engagement. These parameters give rise to a large variety of possible scenarios that need to be studied to assess the viability of a system design and to be able to optimize it with respect to some performance or invested asset metric. For example, Figure 3 shows the case of a
$125 \mathrm{~kW}$ laser powered by one string of 100 lead-acid batteries and fired for 5 seconds at $50 \%$ duty cycle for an extended period of time. It is clear from the plot of laser power that the system has trouble keeping the laser output steady after about 160 seconds, when the state of charge (SOC) of the battery has decayed to less than $70 \%$. Several other cases have been examined with some preliminary results summarized in Figure 4.

100 Genesis XE70 68 Ah Lead Acid Batteries in Series $125 \mathrm{~kW}$ Laser $50 \%$ Duty cycle ( $5 \mathrm{~s}$ on, $5 \mathrm{~s}$ off) for $240 \mathrm{~s}$
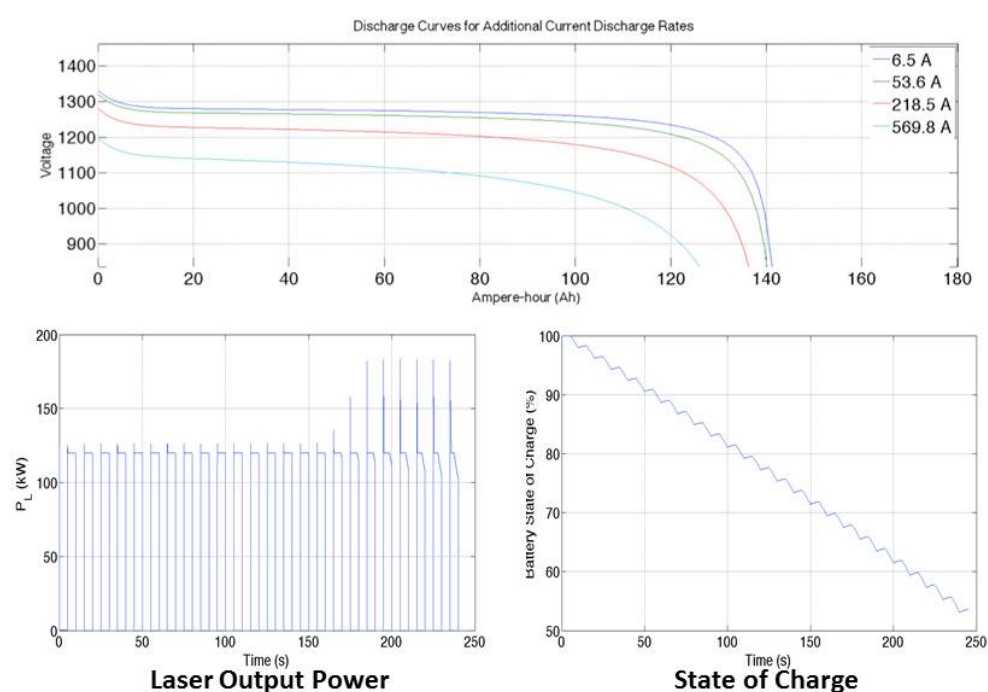

Figure 3: Battery non-linear discharge curve, Laser power and Battery state of charge versus time for a $125 \mathrm{~kW}$ laser with a 5 second pulse, $50 \%$ duty cycle, with one string of 100 lead-acid batteries. 


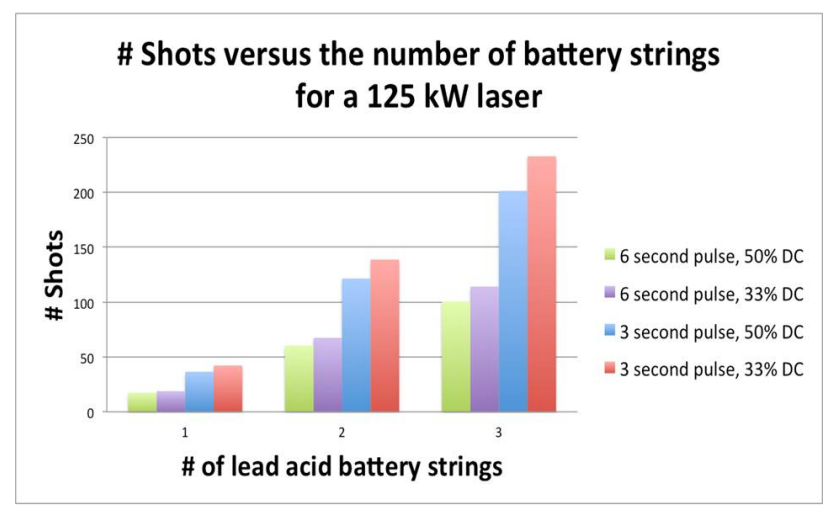

Figure 4: The number of $125 \mathrm{~kW}$ laser pulses (shots) until depletion for different duty cycles and pulse lengths, for 1, 2, or 3 strings of 100 lead-acid batteries for an assumed depletion criterion of $60 \%$ SOC $(\mathrm{DC}=$ duty cycle $)$.

Among the many results of this study, one of the most interesting ones has been that close attention must be paid to the power electronic converters needed to interface the storage modules to the ship power system and to the load. These modules play a crucial role especially for issues of power quality, which can be very important in SSL systems. Furthermore, power electronics can have a major impact on the volume and weight of the storage system.

Figure 5 gives a typical trace of laser voltage versus time for a six second pulse from a $125 \mathrm{~kW}$ laser. The leading edge of the pulse is affected by an overshoot which, if perhaps not excessive, is nevertheless undesirable for a SSL that performs best under nearly ideal dc power conditions. Trying to limit the overshoot with filters may be counterproductive for the pulse rise-time, which is also important. This is a design issue that the model has highlighted and which points to the necessity of further work.

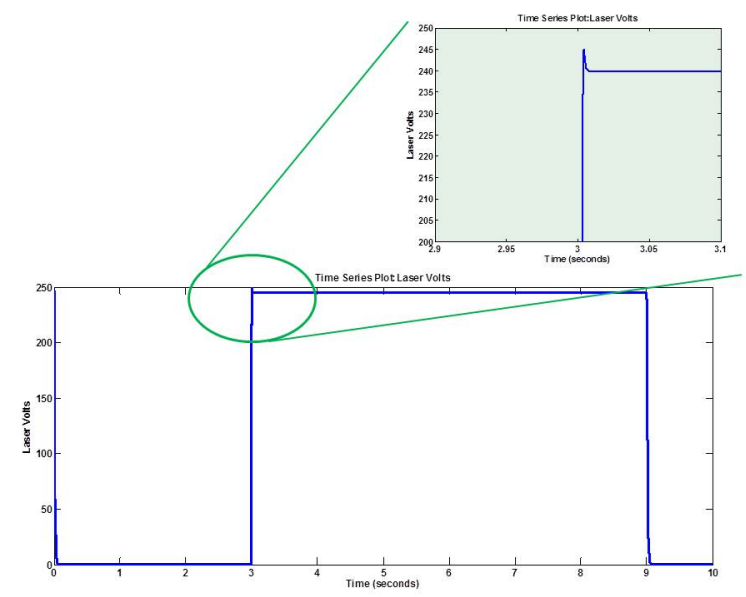

Figure 5: Details of the voltage waveform output to the laser during a 6 second laser shot.

\section{B. Lithium-Ion Batteries}

The model for the system with lithium-ion battery storage is practically identical to the one with lead-acid batteries. The battery used in the model is based on the VL-30 PFe cell by Saft America. The types of analyses and results obtained are similar in nature to the ones for the lead-acid cases provided allowance is made for the different battery characteristics. For example, the lithium ion model uses 270 battery cells per string to provide the necessary $1000 \mathrm{~V}$ at the output of the battery module. The number of strings in parallel has been varied from 1 to 4 for the $50 \%$ and $33 \%$ duty cycle cases. Unlike lead acid batteries, lithium ion batteries can tolerate deep discharges, so they can be considered depleted at the lower value of approximately $20 \%$ state of charge. Plots similar to the ones shown in Figures 3-5 can be obtained also this case.

\section{Flywheel Storage}

The flywheel model was based on data provided by the UTCEM. Flywheels possess some unique characteristics for the energy magazine: rather than the recharge rate being limited by chemical processes, as in a battery, the flywheel recharge rate is only limited by the design of the motor/generator and the supplied power. Although each specific case must be examined in its own right, a typical recharge rate for flywheel energy storage is on the order of minutes.

As was done for the battery, simulations of varying duty cycles and pulse lengths have been performed. A 1\% per second recharge rate has been assumed, so that the loss in rotational speed over time can be calculated. This is an approximation based upon flywheels at UT-CEM. Since the kinetic energy of a rotating mass is proportional to the square of its rotational speed, in theory, $75 \%$ of the flywheel's energy will be depleted at $50 \%$ of its maximum rotational speed. Although there is no operational restriction in slowing a flywheel to zero RPM, it will be considered depleted once the rotational speed reaches approximately $50 \%$ of its rated speed.

The overall model with flywheel energy storage looks outwardly identical to that shown in Figure 2, except that instead of the block labeled "Battery" there is a suitable block containing the model of the flywheel energy storage system. Operationally, the models also work the same way: the flywheel storage is disconnected from the ship power and powers the laser when the laser is activated, whereas it is disconnected from the laser when this is not used and is instead reconnected to ship power for recharging. The electrical diagram for the flywheel energy storage is shown in Figure 6. 


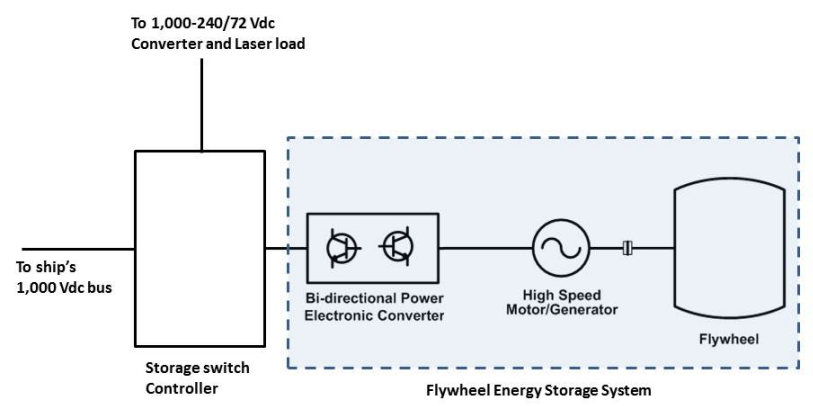

Figure 6: Schematic diagram of the flywheel storage.

The design of a suitable flywheel energy storage introduces a whole new array of variables that can be optimized. Table 1 shows one such array that was considered for the $125 \mathrm{~kW}$ laser case.

Table 1: Various Flywheel designs tested for the $125 \mathrm{~kW}$ laser.

\begin{tabular}{|c|c|c|c|c|c|}
\hline $\begin{array}{c}\text { Power } \\
(\mathrm{MW})\end{array}$ & $\begin{array}{c}\text { Max } \\
\text { Speed } \\
(\mathrm{RPM})\end{array}$ & $\begin{array}{c}\text { Radius } \\
(\mathrm{m})\end{array}$ & $\begin{array}{c}\text { Length } \\
(\mathrm{m})\end{array}$ & $\begin{array}{c}\text { Inertia } \\
\left(\mathrm{kg}^{*} \mathrm{~m}^{2}\right)\end{array}$ & $\begin{array}{c}\text { Energy } \\
\text { Stored } \\
(\mathrm{MJ})\end{array}$ \\
\hline \multirow{3}{*}{17} & 3000 & 0.96 & 0.11 & 1127.5 & 55.6 \\
\cline { 2 - 6 } & 6000 & 0.48 & 0.22 & 140.9 & 27.8 \\
\cline { 2 - 6 } & 12000 & 0.24 & 0.44 & 17.6 & 13.9 \\
\hline \multirow{3}{*}{8.5} & 3000 & 0.96 & 0.06 & 563.7 & 27.8 \\
\cline { 2 - 6 } & 6000 & 0.48 & 0.11 & 70.5 & 13.9 \\
\cline { 2 - 6 } & 12000 & 0.24 & 0.22 & 8.8 & 7.0 \\
\hline \multirow{3}{*}{4} & 3000 & 0.96 & 0.03 & 281.9 & 13.9 \\
\cline { 2 - 6 } & 6000 & 0.48 & 0.06 & 35.2 & 7.0 \\
\cline { 2 - 6 } & 12000 & 0.24 & 0.11 & 4.4 & 3.5 \\
\hline
\end{tabular}

The largest flywheel, $17 \mathrm{MW}$ at $3000 \mathrm{RPM}$, was more than sufficient in meeting the power needs, but would place a large load on the ship's service electrical plant during recharge. The 4MW flywheel was inadequate. In the simulations for smaller power lasers, other flywheels with less power can be used, but for the $125 \mathrm{~kW}$ laser either the $8.5 \mathrm{MW}$ flywheel at $3000 \mathrm{RPM}$ or the $17 \mathrm{MW}$ flywheel at $6000 \mathrm{RPM}$ has enough energy to supply 60,6 -second laser shots at a $50 \%$ duty cycle before depletion, and is comparable to the lead acid and lithium-ion battery storage. Figure 7 shows a typical behavior of a flywheel system under operation with a $125 \mathrm{~kW}$ laser load.

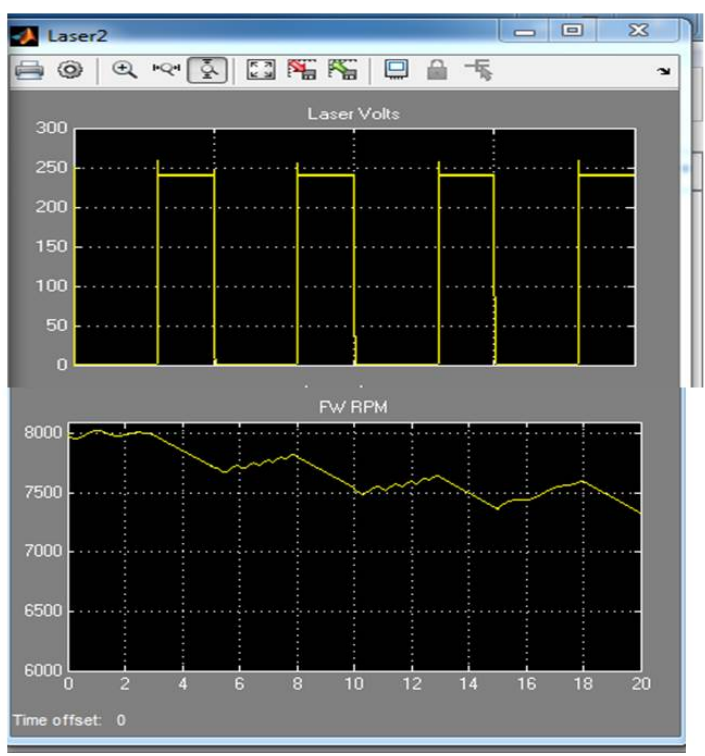

Figure 7: Flywheel speed during recharge cycles.

\section{Capacitor Storage}

The model using capacitors as energy storage was based on the use of capacitor BMOD0063 P125 manufactured by Maxwell Technologies. The basic model architecture is very similar to that shown in Figure 2 with the only significant modification being the addition of an extra dc-dc converter between the ship's power system and the energy storage. This is required because the voltage at the capacitor storage changes considerably during the discharge phase and needs to be properly interfaced with the constant voltage provided by the ship power system.

The simulations that can be run with this model are the same as those with the battery and flywheel storage. One interesting result obtained is that the capacitor storage may actually operate at an average voltage lower than the nominal bus voltage if the recharge time is not sufficient. Figure 8 shows the case where the capacitor voltage drops from the initial $1,000 \mathrm{Vdc}$ to a lower $\sim 850 \mathrm{Vdc}$ average voltage after a few laser pulses, thus behaving as a lower energy storage system than it would be normally capable of (in this case about $72 \%$ of rated energy). This is due to insufficient recharge time for the laser power needed and the duty cycle imposed. However, if the parameters of the problem are properly matched, it may still be possible to support full laser operation for an extended time even at this reduced level of average stored energy. Figure 8 also shows the energy lost in heat at the laser in the last trace. 


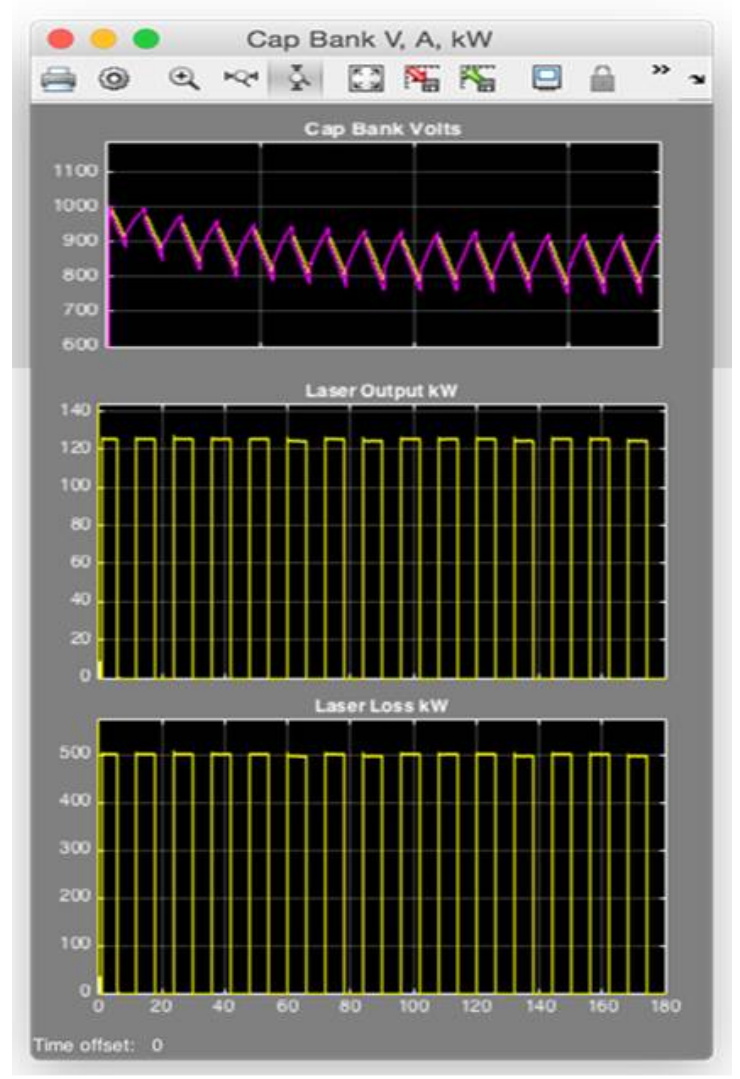

Figure 8: Operation of capacitor storage at lower than nominal bus voltage but still sufficient to support the load.

\section{COMPARATIVE STUDIES}

Since the full destroyer power system has been incorporated in all the models developed (Figure 1), it is possible to conduct with them studies of the effect of the pulse load with energy storage on the ship's power system. It will also be noted from Figure 2 that the user of the models has the option of drawing power at different locations along the ship's power busses, both port and starboard, by simply reconnecting the load at any of the terminals provided. Several studies of ship's power quality can then be conducted. A typical waveform is shown in Figure 9. Notice some slight ripples on the sinusoidal waveform when the laser is off and the battery is being recharged by ship power. These ripples are not a numerical artifact of the model; they are a real physical effect due to non-linear electronic feedback. To minimize effects on other ship electronics, these fluctuations must comply with MIL-STD-1399. Some preliminary results obtained comparing the cases of the two types of battery storage considered are summarized in Table 2.

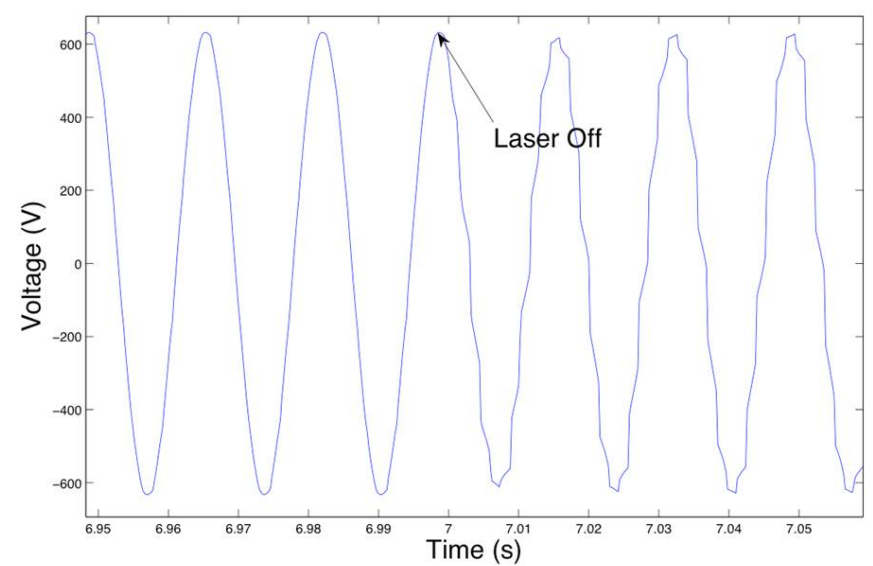

Figure 9: Example of ship's power at the time of transition from laser on to laser off.

Table 2: Comparative changes in dc bus voltage level for some combinations of batteries and laser loads.

\begin{tabular}{|c|c|c|c|c|}
\hline \multicolumn{5}{|c|}{ LEAD ACID } \\
\hline Laser Power & Battery Configuration & $\begin{array}{c}\text { Maximum DC Bus } \\
\text { Voltage Drop } \\
(\%)\end{array}$ & \begin{tabular}{|c|} 
Ship's Power to \\
the Battery \\
(kW)
\end{tabular} & $\begin{array}{l}\text { Ship's Maximum } \\
\text { Current to the Battery } \\
\text { (A) }\end{array}$ \\
\hline $125 \mathrm{~kW}$ & 2 Strings of 100 cells & 7 & 130 & 100 \\
\hline $60 \mathrm{~kW}$ & 1 String of 100 cells & 6 & 120 & 90 \\
\hline $30 \mathrm{~kW}$ & No energy storage & 13 & - & - \\
\hline \multicolumn{5}{|c|}{ LITHIUM ION } \\
\hline Laser Power & Battery Configuration & $\begin{array}{c}\text { Maximum DC Bus } \\
\text { Voltage Drop } \\
(\%)\end{array}$ & $\begin{array}{c}\text { Ship's Power to } \\
\text { the Battery } \\
(\mathrm{kW})\end{array}$ & $\begin{array}{l}\text { Ship's Maximum } \\
\text { Current to the Battery } \\
\text { (A) }\end{array}$ \\
\hline $125 \mathrm{~kW}$ & 2 Strings of 270 cells & 11 & 340 & 320 \\
\hline $60 \mathrm{~kW}$ & 1 String of 270 cells & 12 & 270 & 250 \\
\hline $30 \mathrm{~kW}$ & No energy storage & 13 & - & - \\
\hline
\end{tabular}


The models have also been used to compare the various energy storage methods in regard to their size and weight. Table 3 shows the results of one such analysis. These results are shown to highlight the usefulness of the models more than actual definitive objective data on which decisions can be based regarding the relative suitability of one storage system with respect to another. These studies are very much still in the future.

Table 3: Weight and volume requirements for the some configurations of energy magazines for various laser power levels. These are the minimum configurations required to deliver approximately sixty 6-second shots at a 50\% duty cycle. Note: the flywheel volume and weight is for the rotor only.

\begin{tabular}{|c|c|c|c|}
\hline \multicolumn{4}{|c|}{ LEAD ACID } \\
\hline Laser Power & Battery Configuration & Volume $\left(\mathrm{m}^{3}\right)$ & Weight (kg) \\
\hline $125 \mathrm{~kW}$ & 2 Strings of 100 cells & 1.90 & 5140 \\
\hline $60 \mathrm{~kW}$ & 1 String of 100 cells & 0.95 & 2570 \\
\hline $30 \mathrm{~kW}$ & No energy storage & 0.00 & 0 \\
\hline \multicolumn{4}{|c|}{ LITHIUM ION } \\
\hline Laser Power & Battery Configuration & Volume $\left(\mathrm{m}^{3}\right)$ & Weight (kg) \\
\hline $125 \mathrm{~kW}$ & 2 Strings of 270 cells & 0.26 & 551 \\
\hline $60 \mathrm{~kW}$ & 1 String of 270 cells & 0.13 & 275 \\
\hline $30 \mathrm{~kW}$ & No energy storage & 0.00 & 0 \\
\hline \multicolumn{4}{|c|}{ FLYWHEEL } \\
\hline Laser Power & Flywheel Configuration & Volume $\left(\mathrm{m}^{3}\right)$ & Weight (kg) \\
\hline $125 \mathrm{~kW}$ & $8.5 \mathrm{MW}, 3000$ max RPM & 0.16 & 1238 \\
\hline $60 \mathrm{~kW}$ & $4 \mathrm{MW}, 3000$ max RPM & 0.08 & 608 \\
\hline $30 \mathrm{~kW}$ & No energy storage & 0.00 & 0 \\
\hline
\end{tabular}

\section{CONCLUSIONS}

In a joint research effort, UT-CEM and NPS have developed simulation tools for modeling the integration of laser loads on naval systems. In particular, the following has been achieved:

1. One ship power system completed (destroyer class) with a second one under development

2. Three SSL power levels have been considered so far, with more under study

3. Four storage technologies modeled (lead-acid and lithium-ion batteries, flywheels, and capacitors)

Using these simulation tools, preliminary studies have been performed and typical results for a variety of laser powers, laser duty cycles, and energy storage technologies have been presented herein. It has been shown that the models developed can be used effectively as predictive tools for evaluating the performance of the various systems relative to suitable performance and other metrics.

Once it is incorporated into the ship's electrical system, the energy magazine could also support other planned pulsed loads and can serve the following additional purposes, when not needed for its primary intent of powering pulsed loads:
1. Function as an uninterruptible power supply (UPS) for the ship's power system in case of temporary loss of any of the normal power sources

2. Function as a power ripple leveling when sudden loads are switched on and off the ship's power system.

The effectiveness in carrying out these additional functions can also be studied via the models developed jointly by UTCEM and NPS.

Finally, these ship models allow also the study of the optimal design of the energy storage system architecture: for example, whether storage should be dedicated to the load it is meant to serve or whether it could be shared by multiple loads, or similarly whether storage should be located in close proximity to its main load or could be distributed throughout the power distribution system. Likewise the optimal granularity (number of independent sub-units making up the storage system) of the energy magazine can be evaluated by using these models.

\section{REFERENCES}

[1] LT Oscar Bowlin, "Modeling and Simulation of the Free Electron Laser and Railgun on an Electric Naval Surface Platform", Masters Thesis, Winter 2006, Advisor: W. B. Colson. 
[2] L.N. Domaschk, A. Ouroua, R.E. Hebner, O.E. Bowlin, and W.B. Colson, "Coordination of large pulsed loads on future electric ships," IEEE Transactions on Magnetics, vol. 43, no. 1, part 2, January 2007, pp. 450-455 (PR 404).

[3] ENS Charles Allen III, "Integrating the FEL on an All-Electric Ship", Masters Thesis, Summer 2007, Advisor: W. B. Colson.

[4] R. E. Hebner, A. L. Gattozzi, K. R. Cohn, and W. B. Colson, "Analysis of the power quality impact of multiple directed energy loads on an electric ship power system," in Proc. 2010 23rd Annual Solid State and Diode Laser Technology Review, Colorado, USA (2010).

[5] ENS Ryan Pifer, "Modeling of the Electric Ship", Masters Thesis, Spring 2010, Advisors: W. B. Colson and K. R. Cohn.

[6] LT Michael A. Woehrman, "Power Systems Analysis of a Directed Energy Weapon System for Naval Platforms", Masters Thesis, Winter 2013, Advisors: W. B. Colson and K. R. Cohn.

[7] LT Jeremy E. Sylvester, "Power Systems and Energy Storage Modeling for Directed Energy Weapons", Masters Thesis, Spring 2014, Advisors: W. B. Colson and J. A. Blau. 